\title{
Diabetic impotence: studies of nocturnal erection during REM sleep
}

\author{
D J HOSKING， T BENNET， J R HAMPTON， D F EVANS， A J CLARK， G ROBERTSON
}

British Medical fournal, 1979, 2, 1394-1396

\section{Summary and conclusions}

Nocturnal erections were studied in 30 diabetic patients who complained of impotence and in 11 healthy volunteers. The maximum increase in penile circumference was measured by a penile strain-gauge and recorded on a portable tape-recorder; an external oculogram was recorded simultaneously to identify periods of rapid-eyemovement sleep. The technique gave reproducible results, was acceptable to patients, and was suitable for use in an ordinary hospital ward.

Only six diabetics showed a maximum increase in penile circumference of under $15 \mathrm{~mm}$, whereas all but one of the healthy subjects showed maximum increases above this value. Of the six diabetics, five complained of total impotence and had other features of autonomic neuropathy that suggested an organic basis for their impotence. The other patient complained of partial impotence, which was probably caused by psychological factors. These findings suggest that the prevalence of organic impotence among diabetics has been overestimated.

\section{Introduction}

Although there is general agreement that impotence is commoner in diabetic than non-diabetic men, ${ }^{1}{ }^{2}$ there is less agreement about its cause. Penile erection is a reflex phenomenon depending on integration of psychological and other stimuli with competent neurological and haemodynamic responses. ${ }^{3}$ In non-diabetic subjects psychological factors such as anxiety, resentment, and guilt are the commonest causes of impotence, and structural or metabolic causes account for under $10^{\circ}{ }_{0}$ of cases. ${ }^{4}{ }^{5}$ While this may also be true of diabetics, the common association of disorders of the peripheral vasculature and nervous system in diabetes suggests that diabetic impotence may be more commonly due to vascular insufficiency ${ }^{6}$ or autonomic neuropathy ${ }^{7}$ than to psychological difficulties.

A major difficulty in establishing autonomic neuropathy as a cause of impotence has been the dependence on indirect

University Hospital, Queen's Medical Centre, Nottingham NG7 2UH D J HOSKING, MD, MRCP, senior lecturer in medicine

T BENNET, BSC, PHD, reader in physiology

J R HAMPTON, DM, FRCP, consultant physician

D F EVANS, BA, head technician, department of surgery

A J CLARK, $M B, M R C P$, senior house officer in medicine

$G$ ROBERTSON, MB, BS, senior house officer in medicine measurements of pelvic autonomic function. ${ }^{7}$ " Measurement of penile erections that occur during dreaming (rapid-eyemovement; REM) sleep show that in patients whose impotence is psychogenic, nocturnal erections are normal; patients whose impotence has an organic basis, however, have abnormal erections either awake or asleep. ${ }^{9-12}$ Such studies necessitate the patient's admission to a special sleep laboratory for several nights. We describe a technique that may be used in an ordinary hospital ward to study the nocturnal erections of diabetics who complain of impotence.

\section{Patients and methods}

Nocturnal penile erections were measured in 16 healthy subjects and in 30 diabetic patients who complained of erectile dysfunction. The healthy subjects, who volunteered for the study, were of similar ages to the diabetics (mean 33.5 years, range 23-50) and were recovering either from minor operations or from a traumatic femoral fracture. Half the recordings on the healthy subjects were made in the same ward to which the diabetics were admitted, and the others were made in an orthopaedic ward. Only 11 of the 16 recordings were technically satisfactory, but repeat recordings were not made. All the diabetic patients were admitted specifically for investigation of their impotence. In every case diabetic control was adequate, and none had intercurrent illness. None of the patients were being treated with corticosteroids or androgens, and none had clinical or laboratory evidence of endocrine dysfunction or definite renal disease. Fifteen of the patients complained of total impotence and 15 of partial impotence.

Penile erections during REM sleep were measured with a mercuryin-rubber strain-gauge of $1 \mathrm{~mm}$ external diameter looped around the penis about $2.5 \mathrm{~cm}$ from its base. ${ }^{1: 14}$ The strain-gauge formed one limb of a Wheatstone bridge, so that variations in resistance occurring as the loop stretched during erection could be amplified and recorded on one of the channels of a 24-hour tape-recorder (Oxford Instruments). Use of a calibrated input permitted measurement of the penile erection in absolute terms, and a record was made of the maximum increase in penile circumference. Using skin electrodes over the temples, precordium, and thighs an electro-oculogram (EOG), electrocardiogram (ECG), and electromyogram (EMG) were recorded on the remaining three channels. Analysis of heart-rate variability, EOG, and EMG identified periods of REM sleep, so that changes in penile circumference during these periods could be readily noted.

Cardiovascular autonomic function was assessed separately from these studies using heart-rate variability, the reflex response to standing, and the Valsalva manoeuvre. The practical details of these tests and normal responses have been described. ${ }^{1.5}$ Serum testosterone and prolactin concentrations were measured in venous blood by standard techniques.

\section{Results}

The table gives clinical details of the 15 diabetic patients who complained of partial impotence and of the 15 who had total impotence. There were more patients in the second group with

Clinical features of 30 diabetic patients complaining of impotence. (Means are expressed $\pm S E$ of mean)

\begin{tabular}{|c|c|c|c|c|c|c|c|c|c|c|}
\hline \multirow{2}{*}{$\begin{array}{l}\text { Degree } \\
\text { of } \\
\text { impotence }\end{array}$} & & \multirow{2}{*}{$\begin{array}{c}\text { No of } \\
\text { patients }\end{array}$} & \multirow{2}{*}{$\begin{array}{l}\text { Insulin- } \\
\text { treated }\end{array}$} & \multirow{2}{*}{$\begin{array}{c}\text { Mean } \\
\text { age (years) of }\end{array}$} & \multicolumn{2}{|c|}{ Mean duration (years) of: } & \multicolumn{2}{|c|}{ Neuropathy } & \multirow{2}{*}{ Retinopathy } & \multirow{2}{*}{$\begin{array}{r}\text { Vascula } \\
\text { disease }\end{array}$} \\
\hline & & & & & Diabetes & Impotence & Peripheral & Autonomic & & \\
\hline $\begin{array}{l}\text { Total } \\
\text { Partial }\end{array}$ & .. & $\begin{array}{l}15 \\
15\end{array}$ & $\begin{array}{l}12 \\
10\end{array}$ & $\begin{array}{l}44.73 \div 2.65 \\
42.8 \pm 0.27\end{array}$ & $\begin{array}{l}13 \cdot 8+2 \cdot 88 \\
14 \cdot 1 \pm 2 \cdot 78\end{array}$ & $\begin{array}{l:l}3.42 & 0.54 \\
2.13 & 0.28\end{array}$ & $\begin{array}{l}8 \\
2\end{array}$ & $\begin{array}{l}3 \\
0\end{array}$ & $\begin{array}{l}9 \\
6\end{array}$ & $\begin{array}{l}0 \\
0\end{array}$ \\
\hline
\end{tabular}


retinopathy and peripheral or autonomic neuropathy, but no patient in either group had vascular disease. Six patients complained of impotence when diabetes was first diagnosed. Of the remainder, five had had diabetes for under five years, four for 10-15 years, three for 11-15 years, and 12 for over 15 years before impotence became a problem. Of the 50 recordings taken from the diabetics, 10 were unsuitable because of recorder malfunction or breakage of electrodes or strain-gauge. In these cases the recordings were repeated. Two satisfactory recordings, however, were taken from each of 10 diabetics. Figure 1 shows a reasonable correlation between the maximum changes in penile circumference detected on the two occasions

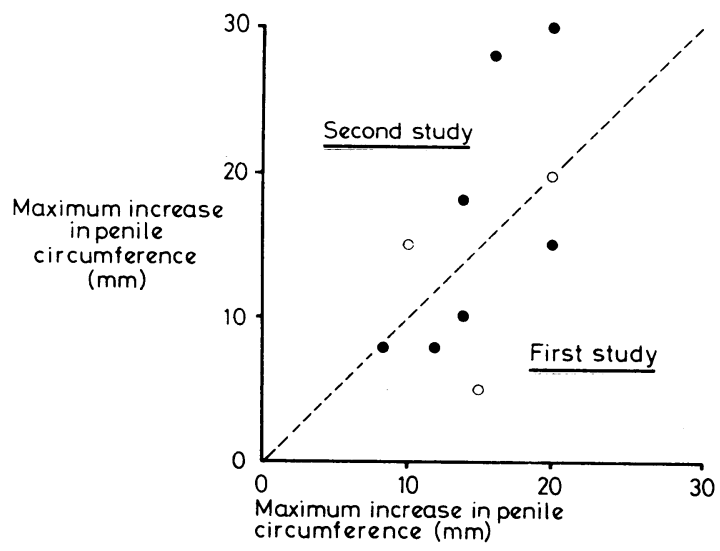

FIG 1-Correlation between first and second studies of nocturnal penile erections in 10 diabetic patients. $O=$ Total impotence. $\mathrm{O}=$ Partial impotence. ---- = Line of equivalence.

Figure 2 shows that in the healthy subjects the maximum increase in penile circumference ranged from 10 to $28 \mathrm{~mm}$ (mean 21.3 $6.0 \mathrm{~mm}$ ). Diabetic patients complaining of total impotence showed maximum increases of 0 to $35 \mathrm{~mm}$ (mean $17 \cdot 7.6 \mathrm{~mm}$ ), and only five of these patients had increases of under $15 \mathrm{~mm}$ in maximum penile circumference. In diabetics complaining of partial impotence maximum increase in penile circumference ranged from 10 to $50 \mathrm{~mm}$ (mean $24.6+10 \cdot 1 \mathrm{~mm}$ ), and only one patient had a maximum increase of under $15 \mathrm{~mm}$. The durations of the erections were also measured. In the healthy subjects these ranged from 15 to 50 minutes (mean 45.416 .5 minutes) and in the diabetics from 20 to 53 minutes

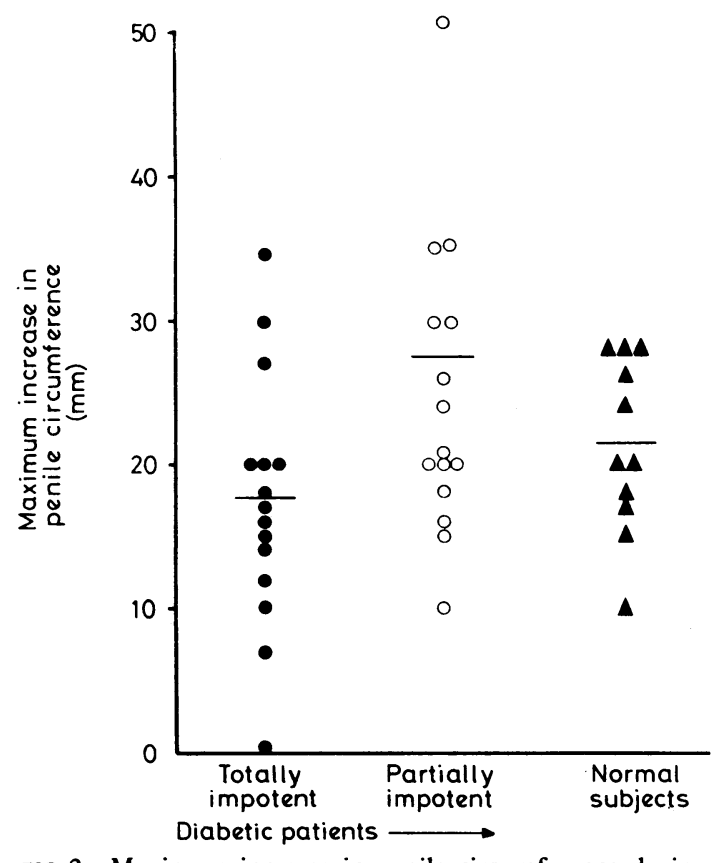

FIG 2-Maximum increase in penile circumference during REM sleep for all subjects. Bars are means. (mean $30 \cdot 7 \div 10 \cdot 16$ minutes). There was poor correlation between the presence of peripheral and autonomic neuropathy and the maximum change in penile circumference in diabetic patients (fig 3 ). Furthermore, there was no useful correlation between the presence of retained libido and morning erections and the maximum increase in penile circumference in these patients (fig 4).

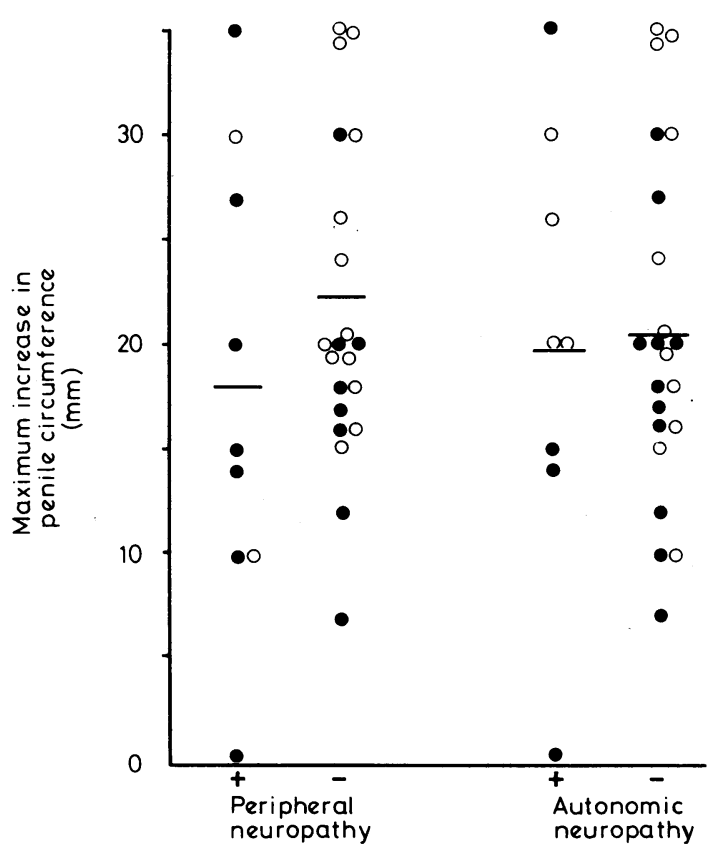

FIG 3-Maximum increase in penile circumference and presence or absence of peripheral or autonomic neuropathy for all diabetic patients. $O=$ Total impotence. $\mathrm{O}=$ Partial impotence. Bars are means.

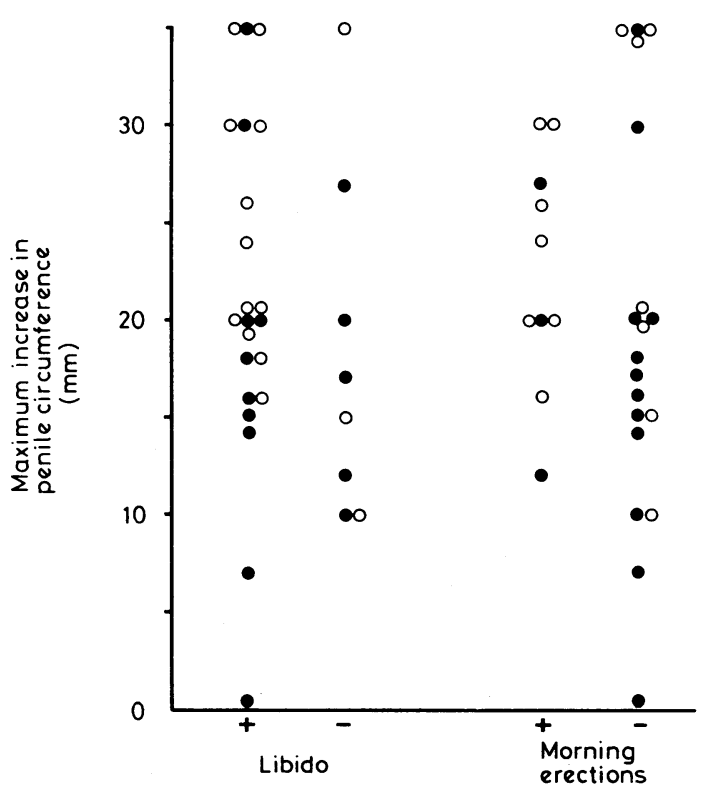

FIG 4-Maximum increase in penile circumference and presence or absence of retained libido or morning erections. $\mathrm{O}=$ Total impotence. $\mathrm{O}=$ Partial impotence.

Serum testosterone and prolactin concentrations were normal in the 20 patients in whom they were measured and showed no relation to the measurements of nocturnal erections. In the diabetics with total impotence the mean serum testosterone concentration was $20 \cdot 1+5 \cdot 6 \mathrm{nmol} / 1 .(5 \cdot 8+1 \cdot 6 \mathrm{ng} / \mathrm{ml}$ ) (normal value $14-42 \mathrm{nmol} / 1$; $4 \cdot 0-12 \cdot 1 \mathrm{ng} / \mathrm{ml}$ ) and the mean serum prolactin concentration $185.112 \mathrm{mU} / 1$ (normal value $100-400 \mathrm{mU} / 1$ ); corresponding values in those with partial impotence were $18 \cdot 8+4 \cdot 7 \mathrm{nmol} / \mathrm{l}(5 \cdot 4 \pm 1 \cdot 3$ $\mathrm{ng} / \mathrm{ml}$ ) and $233148 \mathrm{mU} / \mathrm{l}$. 


\section{Discussion}

This technique is simple to use, and most of the equipment is commercially available. It is acceptable to patients and enables impotence to be investigated in an ordinary, quiet hospital ward simply by admitting the patient for one or two nights. Direct measurements of penile erections correlate poorly with the presence of decreased libido or loss of morning erections ${ }^{7}$ and also with measurements of other aspects of peripheral or autonomic function. We believe that the technique represents a useful advance in the investigation of impotence, and we now use it routinely.

Two-thirds of our diabetic patients had nocturnal erections with an increase in penile circumference and a duration that were within the range shown by the healthy subjects. We cannot imagine an organic lesion that would lead to failure of erection during sexual activity and yet permit normal nocturnal erections, so probably in these patients the impotence was mainly caused by psychological factors. Six diabetics and one healthy subject showed a maximum increase in penile circumference of under $15 \mathrm{~mm}$. The healthy subject, who claimed not to be impotent, was studied only once and on repeated tests might have shown more nocturnal activity, but the diabetics were each studied at least twice. Five of the diabetics complained of total impotence, and all had postural hypotension due to autonomic neuropathy; two also had Charcot's joints. Impotence in these patients may therefore have had an organic basis.

We suggest that in most diabetic patients who complain of impotence the problem is psychological rather than organic, but why impotence should apparently be so common among diabetics is not clear. " Possibly a period of ill health or poor diabetic control causes transient autonomic neuropathy producing reversible organic impotence that might be continued owing to psychological complications. We find that patients are reassured by knowing their impotence does not indicate organic disease, and after this reassurance, or after psychotherapy, some of our patients have reported improved sexual performance.

\section{References}

${ }^{1}$ Rubin, A, and Babbot, D, fournal of the American Medical Association, $1958,168,498$

2 Schoffling, K, et al, Diabetes, 1963, 12, 519.

3 Weiss, H D, Annals of Internal Medicine, 1972, 76, 793.

4 Cooper, A J, British Medical fournal, 1972, 2, 34.

5 Simpson, S L, British Medical fournal, 1950, 1, 692.

6 Herman, A, Adar, R, and Rubinstein, Z, Diabetes, 1978, 27, 975.

${ }^{7}$ Ellenberg, M, Annals of Internal Medicine, 1971, 75, 213.

${ }^{8}$ Campbell, I W, et al, British Medical fournal, 1974, 2, 638.

${ }^{\circ}$ Fisher, C, Gross, J, and Zuch, J, Archives of General Psychiatry, 1965, $12,29$.

10 Karacan, I, et al, Archives of General Psychiatry, 1966, 15, 183

1 Fisher, C, et al, fournal of Sex and Marital Therapy, 1975, 1, 277.

12 Karacan, I, et al, Biological Psychiatry, 1977, 12, 373.

13 Karacan, I, Behaviour Research, Methods and Instrumentation, 1961, 1, 251

${ }^{14}$ Bennet, T, and Evans, D F, fournal of Physiology, 1976, 263, 105.

15 Bennet, T, et al, Diabetes, 1978, 27, 1167.

(Accepted 9 September 1979)
Introduction

Praziquantel* (Embay 8440) is an isoquinoline-pyrazine derivative (2-cyclohexylcarbonyl-1,3,4,6,7,11b-hexahydro- $2 H$-pyrazino (2, 1-a)isoquinoline-4-one) (see figure). It has a broad antiparasitic<smiles>O=C(C1CCCCC1)N1CC(=O)N2CCc3ccccc3C2C1</smiles>

$\mathrm{C}_{19} \mathrm{H}_{24} \mathrm{~N}_{2} \mathrm{O}_{2}$ Molecular weight $312 \cdot 42$

Structure of praziquantel.

effect, and is marketed as a veterinary taeniacide under the trade name Droncit (Bayer). Clinical studies in man have shown that it is also effective in human tapeworm infestation. ${ }^{1}$

There have been several reports on the pronounced biological activity of praziquantel against schistosomes in animals, ${ }^{2-5}$ on its lack of toxicity in man, and on its effectiveness against the three main schistosome species parasitic in man..$^{6-8}$ Schistosoma haema-

*'The compound is a joint development of Bayer AG and E Merck, Germany; the registered trade name for Bayer AG is Biltricide. 